CLINICAL STUDY

\title{
Liraglutide as additional treatment for type 1 diabetes
}

Ajay Varanasi, Natalie Bellini, Deepti Rawal, Mehul Vora, Antoine Makdissi, Sandeep Dhindsa, Ajay Chaudhuri and Paresh Dandona

Division of Endocrinology, Diabetes and Metabolism, State University of New York at Buffalo and Kaleida Health, 3 Gates Circle, Buffalo, New York 14209, USA

(Correspondence should be addressed to P Dandona; Email: pdandona@kaleidahealth.org)

\begin{abstract}
Objective: To determine whether the addition of liraglutide to insulin to treat patients with type 1 diabetes leads to an improvement in glycemic control and diminish glycemic variability.

Subjects and methods: In this study, 14 patients with well-controlled type 1 diabetes on continuous glucose monitoring and intensive insulin therapy were treated with liraglutide for 1 week. Of the 14 patients, eight continued therapy for 24 weeks.

Results: In all the 14 patients, mean fasting and mean weekly glucose concentrations significantly decreased after 1 week from $130 \pm 10$ to $110 \pm 8 \mathrm{mg} / \mathrm{dl}(P<0.01)$ and from $137.5 \pm 20$ to $115 \pm 12 \mathrm{mg} / \mathrm{dl}(P<0.01)$ respectively. Glycemic excursions significantly improved at 1 week. The mean S.D. of glucose concentrations decreased from $56 \pm 10$ to $26 \pm 6 \mathrm{mg} / \mathrm{dl}(P<0.01)$ and the coefficient of variation decreased from $39.6 \pm 10$ to $22.6 \pm 7(P<0.01)$. There was a concomitant fall in the basal insulin from $24.5 \pm 6$ to $16.5 \pm 6$ units $(P<0.01)$ and bolus insulin from $22.5 \pm 4$ to $15.5 \pm 4$ units $(P<0.01)$.

In patients who continued therapy with liraglutide for 24 weeks, mean fasting, mean weekly glucose concentrations, glycemic excursions, and basal and bolus insulin dose also significantly decreased $(P<0.01)$. HbA1c decreased significantly at 24 weeks from 6.5 to $6.1 \%(P=0.02)$, as did the body weight by $4.5 \pm 1.5 \mathrm{~kg}(P=0.02)$.

Conclusion: Liraglutide treatment provides an additional strategy for improving glycemic control in type 1 diabetes. It also leads to weight loss.
\end{abstract}

European Journal of Endocrinology 165 77-84

\section{Introduction}

Since the landmark discovery of insulin by Banting \& Best in 1921 (1), advances in the treatment of type 1 diabetes have centered on preparations of insulin with different rates of absorption from the subcutaneous tissue either through the addition of other proteins like protamine or the creation of analogs of human insulin (2). These modifications led to the availability of insulin preparations, which have either prolonged bioavailability or a more rapid absorption than human insulin. In addition, the continuous subcutaneous insulin infusion (CSII) with the use of pumps has contributed to a more predictable absorption and bioavailability of insulin and thus an improved glucose homeostasis (3). Frequent or continuous glucose monitoring (CGM) may also contribute to an improvement in glycemic control (3).

As an adequate control of glucose homeostasis in patients with type 1 diabetes still continues to be a major challenge, novel means are required to improve it. The arrival of glucagon-like peptide 1 (GLP1) analogs and receptor agonists has not only provided a novel way of controlling hyperglycemia in type 2 diabetics but also the elucidation of the mechanism involved in their action has facilitated the understanding of mechanisms involved in the pathogenesis of postprandial hyperglycemia $(4,5)$. In patients with type 2 diabetes, it has been shown that an increase in glucagon concentrations postprandially contributes to hyperglycemia as hyperglucagonemia results in increased hepatic glucose production $(5,6)$. Normally, the postprandial increase in insulin secretion by the $\beta$-cell leads to the suppression of glucagon secretion by the $\alpha$-cell through paracrine mechanisms (7). The sensitivity of $\alpha$-cells to insulin is maintained in patients with type 2 diabetes (6). However, hyperglucagonemia occurs possibly due to an inadequate postprandial secretion of insulin, or as a result of a possible glucotoxic effect of hyperglycemia on $\alpha$-cell function $(7,8)$. It is possible that a similar pathophysiological disturbance occurs in type 1 diabetes because the lack of insulin secretion by the $\beta$-cell is more severe.

A study showed that native GLP1 improves postprandial hyperglycemia in type 1 diabetics, possibly by the suppression of glucagon (9). Another study 
demonstrated reduction in postprandial glucose after a single exenatide injection in adolescents with type 1 diabetes (10). In view of this and the need of an additional therapeutic strategy in type 1 diabetics, we hypothesized that the use of a GLP1 analog, liraglutide, may help in controlling hyperglycemia and the oscillations in glucose concentrations in this condition. This study describes our experience in 14 patients with type 1 diabetes who were given liraglutide.

\section{Subjects and methods}

This study was conducted at the Diabetes-Endocrinology Center of Western New York at the State University of New York at Buffalo. In this study, 14 patients (nine males and five females) with type 1 diabetes (plasma C-peptide concentrations of $<0.10 \mathrm{nmol} / \mathrm{l}$; positive GAD antibodies) on CSII $(n=13)$ or multiple (four or more) injections of insulin per day $(n=1)$ and using a CGM device were included. All patients who agreed to try liraglutide were included in the study. They were all required to be on a CGM device. Of the 14 patients, eight were on CGM as a part of their long-term management, whereas the remaining six were provided with a CGM for 3 weeks for the study.

Age of subjects ranged from 25 to 52 years (mean: $39.5 \pm 4.8$ years), their body mass index from 19.5 to $29.9 \mathrm{~kg} / \mathrm{m}^{2}$ (mean: $24.0 \pm 2.0 \mathrm{~kg} / \mathrm{m}^{2}$ ), and the duration of diabetes from 12 to 46 years (mean: 24 \pm 4 years). The insulin doses ranged from 12 to 54 $(24.5 \pm 6 \mathrm{U} /$ day) for the basal and from 14 to 59 (22.5 $\pm 5 \mathrm{U} /$ day) for the mealtime (bolus). The mean $\mathrm{HbA1c}$ was $6.6 \pm 0.5 \%$.

All the patients were well versed with carbohydrate counting and self-adjustments of insulin dose on the basis of carbohydrate intake and blood glucose. However, all patients were asked to try and further improve their glycemic control by paying a greater attention to their blood glucose concentrations, dietary intake, carbohydrate counting, adjustment of insulin dose, and the regularization of exercise. Intensification of control was attempted as part of a regular clinic followup visit to target preprandial glucose of $80-120 \mathrm{mg} / \mathrm{dl}$ and $2 \mathrm{~h}$ postprandial glucose of $<140 \mathrm{mg} / \mathrm{dl}$ and minimize hyperglycemic excursions in order to achieve a mean blood glucose of $<130 \mathrm{mg} / \mathrm{dl}$.

As a result of the intensification prior to the administration of liraglutide, there were small increases in the basal insulin dose and in insulin boluses, reductions in carbohydrate intake, and the regularization of exercise. There was no increase in the frequency of hypoglycemic (blood glucose (BG) $<60 \mathrm{mg} / \mathrm{dl}$ ) episodes.

All patients were instructed to inject $0.6 \mathrm{mg}$ liraglutide s.c. daily for 1 week. Patients were asked to reduce their basal insulin by $25 \%$ and bolus by $33 \%$ of their usual dose at the start of liraglutide treatment to avoid hypoglycemia. This reduction was decided after our initial experience with two patients, in whom a reduction of $10 \%$ each for basal and bolus doses had resulted in hypoglycemia. HbAlc was measured within 1-3 weeks prior to starting liraglutide therapy.

CGM data on all patients were collected 1 week prior to treatment with liraglutide (after the patients had intensified their glucose control and were on stable dose of insulin) and for 1 week on liraglutide after a stable dose of insulin had been achieved following the initiation of liraglutide therapy. It took an average of $3 \pm 1$ days to achieve stable insulin doses. In six of the 14 subjects, liraglutide (0.6 mg daily) was discontinued after 1 week because subjects were not able to continue CGM due to cost. In these subjects, CGM was continued for 1 week after the cessation of treatment. Of the 14 patients, eight continued liraglutide for a mean duration of 24 weeks. In these patients, the dose of liraglutide was increased to $1.2 \mathrm{mg}$ daily after 1 week and subsequently to $1.8 \mathrm{mg}$ daily after 2 weeks. Patients who discontinued liraglutide were allowed to adjust their insulin doses upward as appropriate immediately after the cessation of liraglutide. Patients continuing on liraglutide for the longer duration were allowed to reduce their insulin doses further as appropriate during the course of their treatment under our guidance.

All subjects were advised about the possibility of hypoglycemia and the suppression of appetite after the addition of liraglutide and were provided guidance about expected changes in insulin dose after the initiation of liraglutide. Patients were informed about side effects of liraglutide including nausea and vomiting. They were asked to contact the physician on call if they had any side effects. The side effects were evaluated at each visit. An approval was obtained for the

Table 1 Results of patients ( $n=14) 1$ week prior and 1 week during which they attempted to improve their diabetic control with further intensification of treatment by controlling their diets and adjusting their insulin doses. Note that there was no significant change in any of the indices.

\begin{tabular}{lccc}
\hline Parameters & $\begin{array}{c}\text { First } \\
\text { week }\end{array}$ & $\begin{array}{c}\text { Second } \\
\text { week }\end{array}$ & $\boldsymbol{P}$ value \\
\hline HBA1c (\%) & $6.6 \pm 0.5$ & & \\
Insulin dose (U/day) & & & \\
$\quad$ Basal & $24.5 \pm 7$ & $23 \pm 6$ & 0.31 \\
$\quad$ Bolus & $22.5 \pm 4$ & $21 \pm 4$ & 0.36 \\
Mean blood glucose (mg/dl) & & & \\
Fasting & $129.5 \pm 10$ & $127.5 \pm 8$ & 0.28 \\
$\quad$ Weekly & $138 \pm 20$ & $136.5 \pm 12$ & 0.37 \\
Time spent in hyperglycemia (\% time) & & \\
$>150 \mathrm{mg} / \mathrm{dl}$ & $28 \pm 6$ & $26 \pm 5$ & 0.34 \\
$>200 \mathrm{mg} / \mathrm{dl}$ & $18 \pm 5$ & $17.5 \pm 2$ & 0.41 \\
$>250 \mathrm{mg} / \mathrm{dl}$ & $7.0 \pm 2$ & $7.3 \pm 1$ & 0.44 \\
Time spent in hypoglycemia (\% time) & & \\
$\quad<70 \mathrm{mg} / \mathrm{dl}$ & $2.1 \pm 2$ & $2.0 \pm 2$ & 0.32 \\
$\quad<40 \mathrm{mg} / \mathrm{dl}$ & $0.1 \pm 0.2$ & $0.11 \pm 0.3$ & 0.36 \\
Mean s.D. weekly (mg/dl) & $56 \pm 10$ & $54 \pm 6$ & 0.38 \\
Coefficient of variation (\%) & $40.5 \pm 9$ & $39.6 \pm 8$ & 0.38 \\
\hline
\end{tabular}




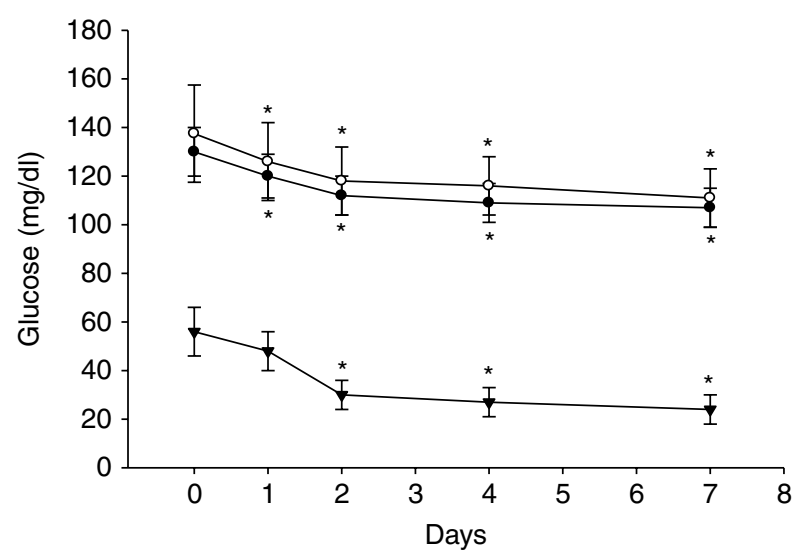

Figure 1 The change in mean blood glucose, fasting blood glucose, and S.D. values at $0,1,2,4$, and 7 days in 14 patients who were treated with liraglutide for 1 week. Open circles: mean blood glucose (mg/dl). Closed circles: mean fasting blood glucose $(\mathrm{mg} / \mathrm{dl})$. Closed triangles: mean s.D. (mg/dl). ${ }^{\star} P<0.05$ as compared to baseline.

retrospective review of the data from the patients' case records from the Human Research Committee of the State University of New York at Buffalo.

\section{Statistical analysis}

Data are presented as mean \pm s.D. Paired $t$-tests were used to compare the change in insulin doses, weight and fasting, and weekly mean blood glucose concentrations prior to and after liraglutide. To evaluate the oscillations in glucose concentrations, s.D. and coefficient of variation $(\mathrm{CV})$ of the mean weekly blood glucose concentration of each patient were also compared using paired $t$-test. $P<0.05$ was considered significant. SPSS Software (SPSS, Inc., Chicago, IL, USA) was used for analysis.

\section{Results}

CGM data from patients prior to liraglutide treatment are presented in Table 1. They show that there was no significant change in the mean fasting and weekly glucose concentrations, s.D. and CV\% of weekly mean glucose concentration, and insulin doses before and after intensification of efforts to improve glycemic control.

\section{Effect of liraglutide on glycemic indices at 1 week}

Fasting mean glucose concentrations significantly fell within $24 \mathrm{~h}$ and mean glucose concentrations significantly fell within $48 \mathrm{~h}$ (Fig. 1) after the institution of liraglutide. During first week of therapy with liraglutide in all the 14 patients, the mean fasting glucose concentrations and weekly mean glucose concentrations significantly decreased $(P<0.01$; Table 2 and
Fig. 2). The mean s.D. of glucose concentrations decreased from $56 \pm 10$ to $26 \pm 6 \mathrm{mg} / \mathrm{dl} \quad(P<0.01)$ and the CV from $39.6 \pm 10$ to $22.6 \pm 7 \%(P<0.01)$. The duration of time spent at a glucose concentration $>150,>200$, and $>250 \mathrm{mg} / \mathrm{dl}$ significantly decreased $(P$ for all $<0.05)$. There was a concomitant fall in the basal insulin $(P<0.05)$ and bolus insulin doses $(P<0.05)$ within 1 week (Table 2 and Fig. 3$)$.

In the six patients who stopped liraglutide after 1 week, the insulin requirements increased and returned to baseline at the end of the first week of withdrawal of liraglutide. The mean fasting blood glucose increased to $130 \pm 10 \mathrm{mg} / \mathrm{dl}$ and the mean weekly blood glucose concentration increased to 143 $\pm 18 \mathrm{mg} / \mathrm{dl}$ while the mean weekly s.D. of glucose concentration increased to $56 \pm 8 \mathrm{mg} / \mathrm{dl}$. These values were almost identical to those prior to treatment (Table 3 and Fig. 4).

\section{The effect of liraglutide on glycemic indices at 24 weeks}

In the eight patients who continued on liraglutide for a mean duration of 24 weeks, the mean fasting glucose $(P<0.05)$ and the weekly mean glucose significantly fell $(P<0.01$; Table 4). The s.D. of mean glucose concentration, $\mathrm{CV}$, the time spent at $>250,>200$ and $>150 \mathrm{mg} / \mathrm{dl}$ in these patients significantly decreased. $(P<0.01$; Table 4$)$. The mean HbAlc significantly fell from 6.5 to $6.1 \%$. There was a reduction in the total daily insulin dose from 0.65 to $0.47 \mathrm{U} / \mathrm{kg}(P<0.05)$.

\section{The effect of liraglutide on body weight}

There was a mean fall in body weight of $0.5 \pm 0.2 \mathrm{~kg}$ at 1 week for all the 14 patients. This was not significant. For those patients who continued liraglutide for

Table 2 Effects of liraglutide treatment for 1 week on 14 patients.

\begin{tabular}{|c|c|c|c|}
\hline Parameters & $\begin{array}{c}\text { Before } \\
\text { treatment } \\
(1 \text { week })\end{array}$ & $\begin{array}{c}\text { On } \\
\text { liraglutide } \\
(1 \text { week })\end{array}$ & $P$ value \\
\hline & \multicolumn{2}{|c|}{ Insulin dose (U/day) } & 0.42 \\
\hline Basal & $24.5 \pm 6$ & $16.5 \pm 6$ & $<0.01$ \\
\hline Bolus & $22.5 \pm 4$ & $15.5 \pm 4$ & $<0.01$ \\
\hline \multicolumn{4}{|l|}{ Mean blood glucose (mg/dl) } \\
\hline Fasting & $130 \pm 10$ & $110 \pm 8$ & $<0.01$ \\
\hline Weekly & $137.5 \pm 20$ & $115 \pm 12$ & $<0.01$ \\
\hline \multicolumn{4}{|c|}{ Time spent in hyperglycemia (\% time) } \\
\hline$>150 \mathrm{mg} / \mathrm{dl}$ & $28 \pm 6$ & $22.5 \pm 5$ & 0.03 \\
\hline$>200 \mathrm{mg} / \mathrm{dl}$ & $18 \pm 5$ & $9 \pm 2$ & $<0.01$ \\
\hline$>250 \mathrm{mg} / \mathrm{dl}$ & $8 \pm 2$ & $1.5 \pm 1$ & $<0.01$ \\
\hline \multicolumn{4}{|c|}{ Time spent in hypoglycemia (\% time) } \\
\hline$<70 \mathrm{mg} / \mathrm{dl}$ & $2.0 \pm 2$ & $2.4 \pm 2$ & 0.06 \\
\hline$<40 \mathrm{mg} / \mathrm{dl}$ & $0.12 \pm 0.2$ & $0.14 \pm 0.3$ & 0.08 \\
\hline Mean weekly s.D. (mg/dl) & $56 \pm 10$ & $26 \pm 6$ & $<0.01$ \\
\hline Coefficient of variation (\%) & $39.6 \pm 10$ & $22.6 \pm 7$ & $<0.01$ \\
\hline
\end{tabular}



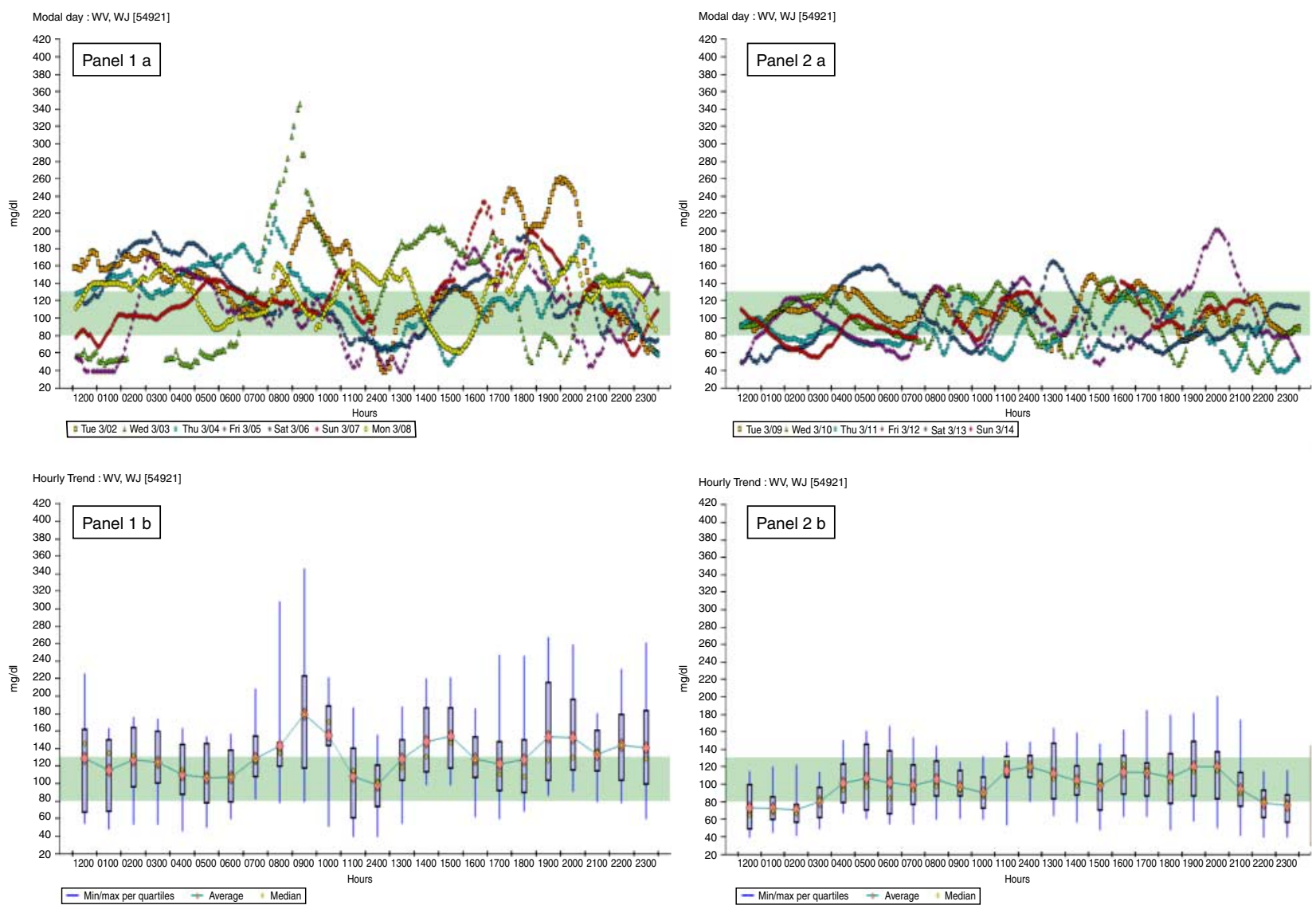

Figure 2 Weekly CGM record (Dexcom) of one patient prior to (panel 1a and b) and following liraglutide (panel 2a and b). Note the glycemic variability and the frequency of glucose concentrations within the target range prior to and following liraglutide. Full colour version of this figure available via http://dx.doi.org/10.1530/EJE-11-0330.

a mean duration of 24 weeks, the body weight fell by $4.5 \pm 1.5 \mathrm{~kg}(P=0.02$; Fig. 5$)$. The weight loss was maximal in the first 12 weeks of starting treatment, $3.5 \pm 1.5 \mathrm{~kg}$; it was $1.0 \pm 0.5 \mathrm{~kg}$ in the next 12 weeks. The decrease in weight was not related to the change in $\mathrm{HbAlc}(r=0.27, P=0.18)$. The patients reported a reduction in appetite with a concomitant reduction in food intake following liraglutide. Unfortunately, we do not have records of their dietary intake.

\section{The effect of liraglutide on hypoglycemic episodes}

There was no significant increase in the duration of hypoglycemia following liraglutide treatment in all the 14 patients: time spent at $<70 \mathrm{mg} / \mathrm{dl}$ and time spent at $<40 \mathrm{mg} / \mathrm{dl}$ (see Table 2). In patients on liraglutide treatment for 24 weeks, the time spent at $<70$ and $<40 \mathrm{mg} / \mathrm{dl}$ prior to liraglutide and after liraglutide was not significant. Approximately $75 \%$ of recorded hypoglycemia was nocturnal at both $(<70$ and $<40 \mathrm{mg} / \mathrm{dl}$ ) blood glucose levels. Perceived hypoglycemia was reported more frequently early after the initiation of liraglutide but it diminished with further appropriate reductions in the insulin dose. There was no severe hypoglycemic episode requiring intervention by others.

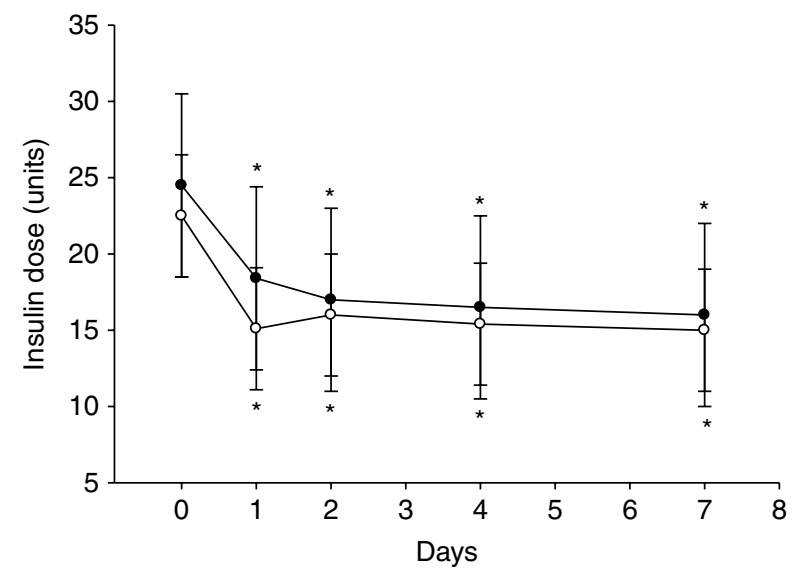

Figure 3 The change in insulin dose over 7-day duration in 14 patients treated with liraglutide for 1 week. Open circles: bolus insulin. Closed circles: basal insulin. ${ }^{*} P<0.05$ as compared to baseline. 

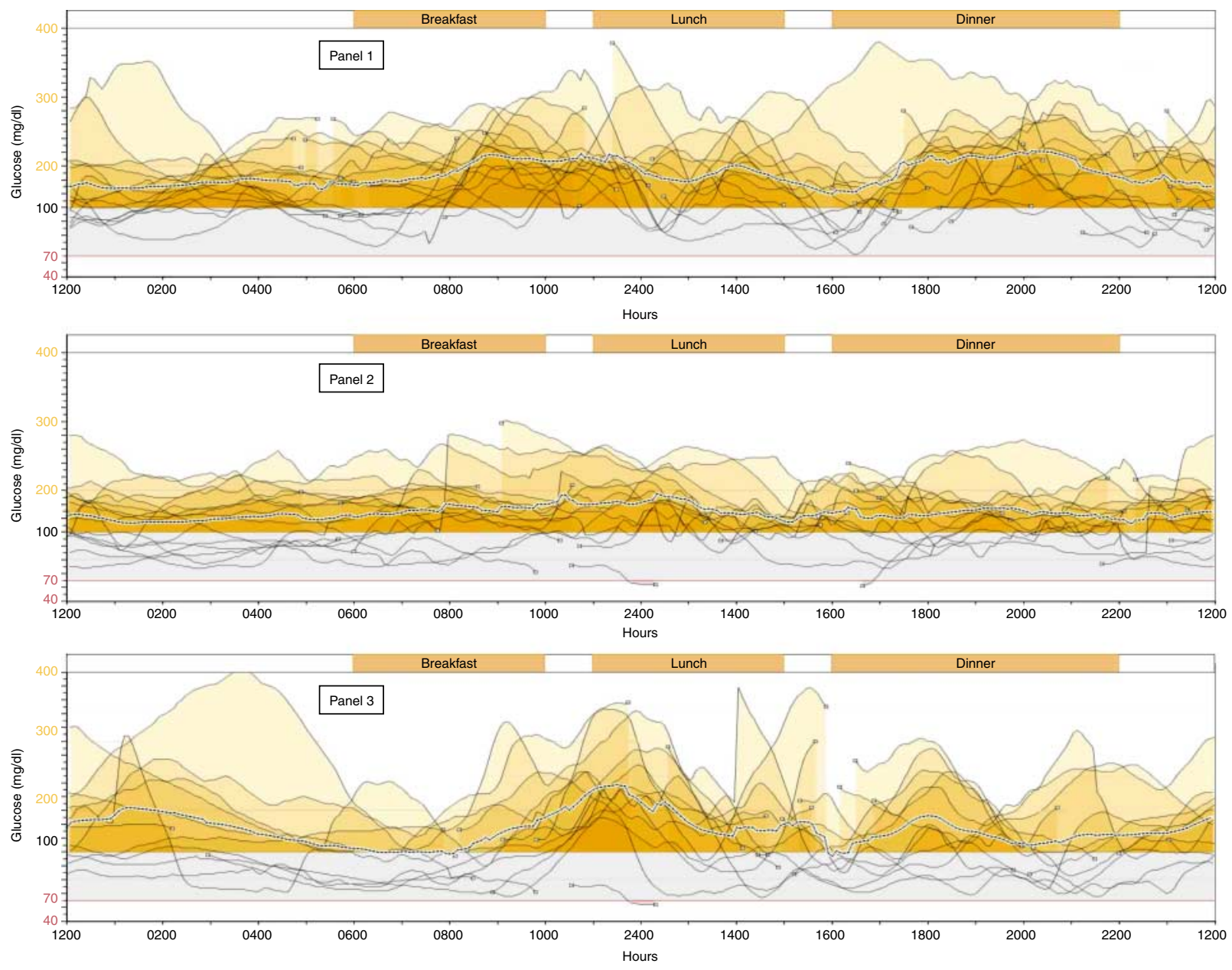

Figure 4 Weekly continuous glucose monitoring record (Medtronic) on one patient prior to, during, and after liraglutide treatment. Note the glycemic variability and the frequency of glucose concentrations within the target range prior to (panel 1), during (panel 2), and following (panel 3) liraglutide. Full colour version of this figure available via http://dx.doi.org/10.1530/EJE-11-0330.

\section{The effect of liraglutide on C-peptide}

Fasting C-peptide concentrations measured in eight patients after 24 weeks of treatment were still undetectable $(<0.10 \mathrm{nmol} / \mathrm{l})$. Two patients experienced nausea, constipation, and headache after starting liraglutide but all the side effects resolved after 2-3 days of treatment.

\section{Discussion}

Our data show that the mean fasting glucose and the mean weekly glucose concentrations and the time spent with hyperglycemia decreased after the addition of liraglutide in spite of the reduction in the dose of insulin in subjects with type 1 diabetes. The oscillations of blood glucose concentrations also significantly diminished as reflected in the reduction in mean S.D. and CV of

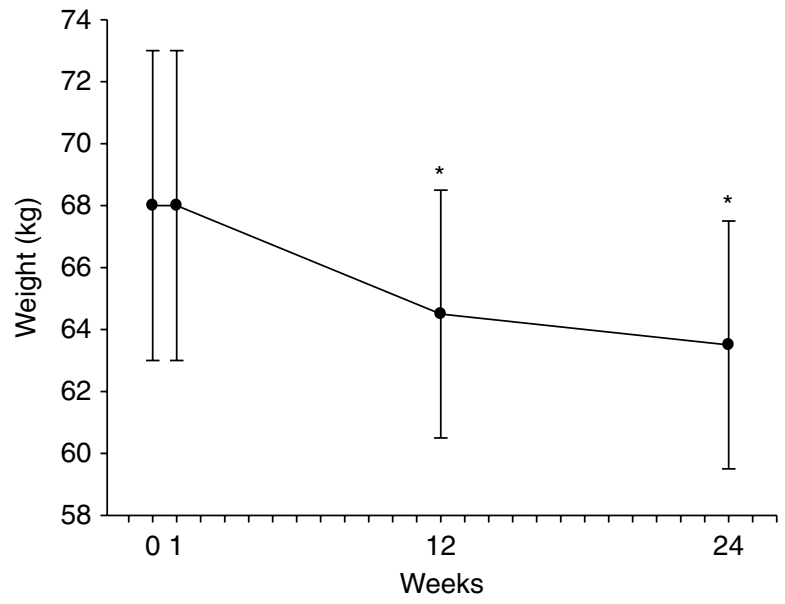

Figure $\mathbf{5}$ The change in weight of eight patients who continued liraglutide for 24 weeks at $0,1,12$, and 24 weeks. ${ }^{*} P<0.05$ as compared to baseline. 
Table 3 Results of patients $(n=6) 1$ week prior, 1 week during and one after stopping liraglutide. Note that there was a reversal of all characteristics to baseline.

\begin{tabular}{|c|c|c|c|c|c|c|}
\hline Parameters & $\begin{array}{c}\text { Before } \\
\text { treatment } \\
(1 \text { week })\end{array}$ & $\begin{array}{c}\text { On } \\
\text { liraglutide } \\
\text { (1 week })\end{array}$ & $P$ value & $\begin{array}{c}\text { Post } \\
\text { liraglutide } \\
\text { (1 week })\end{array}$ & $P$ value & $\begin{array}{c}P \text { value before } \\
\text { and after } \\
\text { liraglutide }\end{array}$ \\
\hline \multicolumn{7}{|l|}{ Insulin dose (U/day) } \\
\hline Basal & $22.0 \pm 6$ & $15.5 \pm 6$ & $<0.01$ & $23 \pm 6$ & $<0.01$ & 0.51 \\
\hline Bolus & $18.8 \pm 4$ & $14.5 \pm 4$ & $<0.01$ & $20 \pm 4$ & $<0.01$ & 0.36 \\
\hline \multicolumn{7}{|l|}{ Mean blood glucose $(\mathrm{mg} / \mathrm{dl})$} \\
\hline Fasting & $132.5 \pm 10$ & $113 \pm 8$ & $<0.01$ & $130 \pm 10$ & $<0.01$ & 0.58 \\
\hline Weekly & $148 \pm 18$ & $118 \pm 12$ & $<0.01$ & $143 \pm 18$ & $<0.01$ & 0.39 \\
\hline \multicolumn{7}{|c|}{ Time spent in hyperglycemia (\% time) } \\
\hline$>150 \mathrm{mg} / \mathrm{dl}$ & $28.62 \pm 6$ & $21.5 \pm 5$ & $<0.01$ & $27.6 \pm 6$ & $<0.01$ & 0.54 \\
\hline$>200 \mathrm{mg} / \mathrm{dl}$ & $18.63 \pm 5$ & $10 \pm 2$ & $<0.01$ & $17.8 \pm 5$ & $<0.01$ & 0.46 \\
\hline$>250 \mathrm{mg} / \mathrm{dl}$ & $8 \pm 2$ & $2.0 \pm 1$ & $<0.01$ & $7.5 \pm 2$ & $<0.01$ & 0.54 \\
\hline \multicolumn{7}{|c|}{ Time spent in hypoglycemia (\% time) } \\
\hline$<70 \mathrm{mg} / \mathrm{dl}$ & $2.12 \pm 2$ & $2.3 \pm 2$ & 0.08 & $2.2 \pm 2$ & 0.16 & 0.36 \\
\hline$<40 \mathrm{mg} / \mathrm{dl}$ & $0.13 \pm 0.2$ & $0.14 \pm 0.3$ & 0.13 & $0.13 \pm 0.2$ & 0.12 & 0.66 \\
\hline Mean S.D. weekly (mg/dl) & $59.75 \pm 10$ & $28 \pm 6$ & $<0.01$ & $56 \pm 8$ & $<0.01$ & 0.39 \\
\hline Coefficient of variation (\%) & $40 . \overline{3} 8$ & 23.8 & $<0.01$ & 39.2 & $<0.01$ & 0.48 \\
\hline
\end{tabular}

blood glucose concentrations. As visualized in the figures, both the peaks and the troughs of glucose concentrations diminished. In association with these improvements, there was a marked reduction in the dose of insulin required and a simultaneous reduction in body weight. Those patients in whom liraglutide was discontinued, the original doses of insulin had to be restored and the glycemic excursions observed prior to liraglutide also returned.

These improvements were observed within 1-2 days of the initiation of liraglutide and they reversed within a similar period after the discontinuation of the drug. The rapid return of the glucose concentrations, the s.D., and the insulin doses to preliraglutide levels also indicate that they have most likely occurred as a result of the effects of treatment with liraglutide. Furthermore, as the improvement in glycemic control occurred within 1 week, this improvement cannot be attributed to the weight loss that followed. Even though the intensification of treatment regimen prior to starting liraglutide may have contributed to $\beta$-cell rest and glycemic control in itself, data obtained from CGM following the intensification regimen still showed significant oscillations in glucose concentration that significantly improved following initiation of treatment with liraglutide.

Those patients in whom the treatment with liraglutide was continued, the improvement in the glycemic pattern was persistent. Although there was no further improvement either in the glucose concentrations or in the S.D. following longer period of treatment, there was a further reduction in insulin dose. The reductions in carbohydrate and food intake and body weight following liraglutide may have contributed to this.

These observations raise questions about the mechanisms underlying such rapid changes in glucose homeostasis following liraglutide in type 1 diabetics. The first possibility is that liraglutide may have suppressed the increase in glucagon concentration after meals (11). The near total absence of $\beta$-cell function in type 1 diabetics would suggest that there is no inhibition of glucagon secretion postprandially through the local paracrine inhibitory effect of insulin. Therefore, it is likely that there is a significant increase in glucagon secretion in these patients after meals. It is possible that liraglutide suppresses this. There are recent data demonstrating that GLP1 infusion induces a significant suppression of the basal and arginine-induced increase in the plasma concentration of glucagon in type 1 diabetics (12).

Another mechanism to explain the reduction in the duration of hyperglycemia could be the decrease in postprandial glucose excursion due to the slowing of gastric emptying, which is known to occur with liraglutide (11). However, this does not explain the lowering of fasting glucose in these subjects.

Table 4 Effects of liraglutide treatment for a mean duration of 24 weeks in eight patients.

\begin{tabular}{|c|c|c|c|}
\hline Parameters & $\begin{array}{c}\text { Before } \\
\text { treatment } \\
(1 \text { week })\end{array}$ & $\begin{array}{c}\text { On } \\
\text { liraglutide } \\
\text { (24 weeks) }\end{array}$ & $P$ value \\
\hline Weight (kg) & $68 \pm 5$ & $63.5 \pm 4$ & 0.02 \\
\hline HBA1c (\%) & $6.5 \pm 0.5$ & $6.1 \pm 0.4$ & 0.02 \\
\hline \multicolumn{4}{|l|}{ Insulin dose (U/day) } \\
\hline Basal & $26.5 \pm 7$ & $13.5 \pm 5$ & $<0.01$ \\
\hline Bolus & $25.5 \pm 6$ & $14 \pm 4$ & $<0.01$ \\
\hline \multicolumn{4}{|l|}{ Mean blood glucose $(\mathrm{mg} / \mathrm{dl})$} \\
\hline Fasting & $128 \pm 10$ & $108 \pm 8$ & $<0.01$ \\
\hline Weekly & $134 \pm 20$ & $111 \pm 12$ & $<0.01$ \\
\hline \multicolumn{4}{|c|}{ Time spent in hyperglycemia (\% time) } \\
\hline$>150 \mathrm{mg} / \mathrm{dl}$ & $27.5 \pm 6$ & $21 \pm 5$ & 0.02 \\
\hline$>200 \mathrm{mg} / \mathrm{dl}$ & $17.5 \pm 5$ & $6.5 \pm 2$ & $<0.01$ \\
\hline$>250 \mathrm{mg} / \mathrm{dl}$ & $8.0 \pm 2$ & $2.0 \pm 1$ & $<0.01$ \\
\hline \multicolumn{4}{|c|}{ Time spent in hypoglycemia (\% time) } \\
\hline$<70 \mathrm{mg} / \mathrm{dl}$ & 2.1. \pm 2 & $2.3 \pm 2$ & 0.08 \\
\hline$<40 \mathrm{mg} / \mathrm{dl}$ & $0.11 \pm 0.2$ & $0.12 \pm 0.3$ & 0.12 \\
\hline Mean S.D. weekly (mg/dl) & $53 \pm 10$ & $27 \pm 6$ & $<0.01$ \\
\hline Coefficient of variation weekly (\%) & $39.5 \pm 10$ & $24.3 \pm 8$ & $<0.01$ \\
\hline
\end{tabular}


Although patients with long standing type 1 diabetes do not have significant insulin secretion, it has been shown that they have a significant $\beta$-cell population that is not fully differentiated (13-15). It is possible that long-term treatment may facilitate full differentiation of these cells and restore some insulin secretion. This potential mechanism is probably not relevant following the short-term treatment described here, especially as there was no significant change in fasting C-peptide concentration after liraglutide treatment. The study on the effect of exenatide in type 1 diabetics by Rother et al. (16) demonstrated an increase in insulin secretion over a period of several months but this was not considered to be clinically significant.

The weight loss and the associated suppression of appetite even over the short period of treatment are of interest. Liraglutide is known to exert an appetite suppressive effect (11). This effect of liraglutide is important because $40-50 \%$ of patients with type 1 diabetes in the US concomitantly have the metabolic syndrome (17). At 12 years of follow-up, 30\% of patients with type 1 diabetes in Diabetes Control and Complications Trial/Epidemiology of Diabetes Interventions and Complications Trial were obese (18). A similar high proportion of children (30\%) with type 1 diabetes are either overweight or obese (19). The suppression of appetite by liraglutide may have also contributed to the improved glycemic control and the continued reduction in the dose of insulin required. However, weight loss was not necessary for the reduction in insulin dose as the latter occurred within the first 2 days of the initiation of liraglutide therapy. The reduction in body weight has implications in terms of cardiovascular complications. In addition, liraglutide has been shown to reduce systolic blood pressure like exenatide. This may also potentially help in the reduction of cardiovascular outcomes (20-24).

The major weakness of this study is that it was not placebo controlled and not carried out double blind. However, this study provides the initial proof of principle on the basis of which future double-blind crossover studies need to be carried out to confirm the findings reported in this study. The other limitation of this study is that we cannot generalize our observations to all patients with type 1 diabetes because the patients included in this study were meticulous, disciplined and their HbA1c, well controlled, based on who significantly improved following this treatment.

In conclusion, the addition of liraglutide to insulin therapy in well-controlled type 1 diabetics resulted in a significant and rapid reduction in glycemic excursions with a concomitant reduction in insulin dose. These glycemic effects were rapidly reversed after the cessation of liraglutide treatment. There was also a reduction in appetite and food intake. Body weight significantly fell in the group followed up for 24 weeks. These observations warrant a detailed investigation into the efficacy of liraglutide and other GLP1 agonists in the treatment of type1 diabetes and the pathophysiological mechanisms underlying these effects, including prospective randomized double-blind trials.

\section{Declaration of interest}

The authors declare that there is no conflict of interest that could be perceived as prejudicing the impartiality of the research reported.

\section{Funding}

This research did not receive any specific grant from any funding agency in the public, commercial or not-for-profit sector. P Dandona (SUNY at Buffalo) was supported by NIDDK (-NIH: R01DK069805-02, R01DK075877-01-A2, and ADA: 08-CR-13) while S Dhindsa (SUNY at Buffalo) was supported by ADA 10-JF-13.

\section{Author Contributions}

A Varanasi: planning, execution, writing; N Bellini: hypothesis, planning; M Vora: execution; D Rawal: execution; S Dhindsa: statistical analysis, interpretation; A Makdissi: statistical analysis, interpretation; A Chaudhuri: interpretation, writing; P Dandona: hypothesis, interpretation, writing.

\section{Acknowledgements}

The authors thank the help of the Diabetes Educators, Donna Kain (Kaleida Health) and Sue Nielsen (Kaleida Health), and the staff at the Diabetes Endocrinology Center of Western New York (Kaleida Health).

\section{References}

1 Banting FG \& Best CH. Internal secretion of pancreas. Journal of Laboratory and Clinical Medicine 1922 7 464-480.

2 Hahr AJ \& Molitch ME. Optimizing insulin therapy in patients with type 1 and type 2 diabetes mellitus: optimal dosing and timing in the outpatient setting. American Journal of Therapeutics $2008 \mathbf{1 5}$ 543-550. (doi:10.1097/MJT.0b013e31815aeb79)

3 Tamborlane WV, Beck RW, Bode BW, Buckingham B, Chase HP, Clemons R, Fiallo-Scharer R, Fox LA, Gilliam LK, Hirsch IB, Huang ES, Kollman C, Kowalski AJ, Laffel L, Lawrence JM, Lee J, Mauras N, O'Grady M, Ruedy KJ, Tansey M, Tsalikian E, Weinzimer S, Wilson DM, Wolpert H, Wysocki T \& Xing D. Continuous glucose monitoring and intensive treatment of type 1 diabetes. New England Journal of Medicine 2008359 1464-1476. (doi:10.1056/NEJMoa0805017)

4 Fonseca VA, Zinman B, Nauck MA, Goldfine AB \& Plutzky J. Confronting the type 2 diabetes epidemic: the emerging role of incretin-based therapies. American Journal of Medicine 2010123 S2-S10. (doi:10.1016/j.amjmed.2010.04.002)

5 Cervera A, Wajcberg E, Sriwijitkamol A, Fernandez M, Zuo P, Triplitt C, Musi N, DeFronzo RA \& Cersosimo E. Mechanism of action of exenatide to reduce postprandial hyperglycemia in type 2 diabetes. American Journal of Physiology. Endocrinology and Metabolism $2008 \mathbf{2 9 4}$ E846-E852. (doi:10.1152/ajpendo. 00030.2008)

6 Baron AD, Schaeffer L, Shragg P \& Kolterman OG. Role of hyperglucagonemia in maintenance of increased rates of hepatic glucose output in type II diabetics. Diabetes 198736 274-283. (doi:10.2337/diabetes.36.3.274) 
7 Gerich JE, Charles MA \& Grodsky GM. Regulation of pancreatic insulin and glucagon secretion. Annual Review of Physiology 1976 38 353-388. (doi:10.1146/annurev.ph.38.030176.002033)

8 Abdul-Ghani M \& DeFronzo RA. Fasting hyperglycemia impairs glucose but not insulin-mediated suppression of glucagon secretion. Journal of Clinical Endocrinology and Metabolism 2007 92 1778-1784. (doi:10.1210/jc.2006-1515)

9 Dupré J, Behme MT \& McDonald TJ. Exendin-4 normalized postcibal glycemic excursions in type 1 diabetes. Journal of Clinical Endocrinology and Metabolism 200489 3469-3473. (doi:10. 1210/jc.2003-032001)

10 Raman VS, Mason KJ, Rodriguez LM, Hassan K, Yu X, Bomgaars L \& Heptulla RA. The role of adjunctive exenatide therapy in pediatric type 1 diabetes. Diabetes Care 201033 1294-1296. (doi:10.2337/dc09-1959)

11 Lovshin JA \& Drucker DJ. Incretin-based therapies for type 2 diabetes mellitus. Nature Reviews. Endocrinology $20095262-269$. (doi:10.1038/nrendo.2009.48)

12 Kielgast U, Asmar M, Madsbad S \& Holst JJ. Effect of glucagon-like peptide- 1 on alpha- and beta-cell function in C-peptide-negative type 1 diabetic patients. Journal of Clinical Endocrinology and Metabolism 2010 95 2492-2496. (doi:10.1210/jc.2009-2440)

13 Brennand K \& Melton D. Slow and steady is the key to beta-cell replication. Journal of Cellular and Molecular Medicine 200913 472-487. (doi:10.1111/j.1582-4934.2008.00635.x)

14 Meier JJ, Bhushan A, Butler AE, Rizza RA \& Butler PC. Sustained beta cell apoptosis in patients with long-standing type 1 diabetes: indirect evidence for islet regeneration? Diabetologia $2005 \mathbf{4 8}$ 2221-2228. (doi:10.1007/s00125-005-1949-2)

15 Bosi E. Time for testing incretin therapies in early type 1 diabetes? Journal of Clinical Endocrinology and Metabolism $2010952607-$ 2609. (doi:10.1210/jc.2009-2741)

16 Rother KI, Spain LM, Wesley RA, Digon BJ III, Baron A, Chen K, Nelson P, Dosch HM, Palmer JP, Brooks-Worrell B, Ring M \& Harlan DM. Effects of exenatide alone and in combination with daclizumab on beta-cell function in long-standing type 1 diabetes. Diabetes Care 200932 2251-2257. (doi:10.2337/dc09-0773)

17 Wajchenberg BL, Feitosa AC, Rassi N, Lerario AC \& Betti RT. Glycemia and cardiovascular disease in type 1 diabetes mellitus. Endocrine Practice 200814 912-923.
18 Larkin ME, Backlund JY, Cleary P, Bayless M, Schaefer B, Canady J \& Nathan DM. Disparity in management of diabetes and coronary heart disease risk factors by sex in DCCT/EDIC. Diabetic Medicine 201027 451-458. (doi:10.1111/j.1464-5491. 2010.02972.x)

19 Luczyński W, Szypowska A, Głowińska-Olszewska B \& Bossowski A. Overweight, obesity and features of metabolic syndrome in children with diabetes treated with insulin pump therapy. European Journal of Pediatrics 2010. (doi:10.1007/ s00431-010-1372-7)

20 Viswanathan P, Chaudhuri A, Bhatia R, Al-Atrash F, Mohanty P \& Dandona P. Exenatide therapy in obese patients with type 2 diabetes mellitus treated with insulin. Endocrine Practice 200713 444-450.

21 Buse JB, Klonoff DC, Nielsen LL, Guan X, Bowlus CL, Holcombe JH, Maggs DG \& Wintle ME. Metabolic effects of two years of exenatide treatment on diabetes, obesity, and hepatic biomarkers in patients with type 2 diabetes: an interim analysis of data from the openlabel, uncontrolled extension of three double-blind, placebocontrolled trials. Clinical Therapeutics $2007 \quad 29$ 139-153. (doi:10.1016/j.clinthera.2007.01.015)

22 Okerson T, Yan P, Stonehouse A \& Brodows R. Effects of exenatide on systolic blood pressure in subjects with type 2 diabetes. American Journal of Hypertension 201023 334-339. (doi:10. 1038/ajh.2009.245)

23 Varanasi A, Chaudhuri A, Dhindsa S, Arora A, Lohano T, Vora M \& Dandona P. Durability of effects of exenatide treatment on glycemic control, body weight, systolic blood pressure, Crp and triglyceride concentrations. Endocrine Practice 201117 192-200. (doi:10.4158/EP10199.OR)

24 Montanya E \& Sesti G. A review of efficacy and safety data regarding the use of liraglutide, a once-daily human glucagon-like peptide 1 analogue, in the treatment of type 2 diabetes mellitus. Clinical Therapeutics 200931 2472-2488. (doi:10.1016/j.clinthera.2009.11.034)

Received 13 April 2011

Accepted 26 April 2011 